\title{
Experimental Non-O Group 1 Vibrio cholerae Gastroenteritis in Humans
}

\author{
J. Glenn Morris, Jr.," Tae Takeda, ${ }^{*}$ Ben D. Tall, " Genevieve A. Losonsky, ${ }^{*}$ Sujit K. Bhattacharya, ${ }^{\ddagger 5}$ \\ Bruce D. Forrest," Bradford A. Kay," and Mitsuaki Nishibuchi' \\ *Division of Geographic Medicine, Department of Medicine, and Center for Vaccine Development, University of Maryland School of \\ Medicine, Baltimore, Maryland 21201; ${ }^{\ddagger}$ Department of Infectious Diseases Research, National Children's Medical Research Center, \\ Tokyo, 154 Japan; ${ }^{\S}$ National Institute of Cholera and Enteric Diseases, Calcutta, India; "Department of Clinical Sciences, \\ London School of Hygiene and Tropical Medicine, London WCIE 7HT, United Kingdom; and "Department of Microbiology, \\ Faculty of Medicine, Kyoto University, Kyoto, 606 Japan
}

\begin{abstract}
In this study, 27 volunteers received one of three non-O group 1 Vibrio cholerae strains in doses as high as $10^{9}$ CFU. Only one strain (strain C) caused diarrhea: this strain was able to colonize the gastrointestinal tract, and produced a heat-stable enterotoxin (NAG-ST). Diarrhea was not seen with a strain (strain A) that colonized the intestine but did not produce NAG-ST, nor with a strain (strain B) that produced NAG-ST but did not colonize. Persons receiving strain $\mathrm{C}$ had diarrhea and abdominal cramps. Diarrheal stool volumes ranged from 154 to $5,397 \mathrm{ml}$; stool samples from the patient having 5,397 $\mathrm{ml}$ of diarrhea were tested and found to contain NAG-ST. The median incubation period for illness was $10 \mathrm{~h}$. There was a suggestion that occurrence of diarrhea was dependent on inoculum size. Immune responses to homologous outer membrane proteins, lipopolysacchide, and whole-cell lysates were demonstrable with all three strains.

Our data demonstrate that $\boldsymbol{V}$. cholerae of $\mathrm{O}$ groups other than $I$ are able to cause severe diarrheal disease. However, not all strains are pathogenic for humans: virulence of strain $\mathbf{C}$ may be dependent on its ability both to colonize the intestine and to produce a toxin such as NAG-ST. (J. Clin. Invest. 1990. 85:697-705.) non-O1 Vibrio cholerae heat-stable enterotoxin - infectious diarrhea $\bullet$ antibody-secreting cells • oysters
\end{abstract}

\section{Introduction}

Vibrio cholerae are classified according to $O$ group (1-3), with strains of $\mathrm{O}$ group $1(V \text {. cholerae } \mathrm{O} 1)^{1}$ responsible for the disease cholera $(4,5)$. The role played by strains of $O$ groups other

Address reprint requests to Dr. Morris, Division of Geographic Medicine, University of Maryland School of Medicine, 10 South Street, Baltimore, MD 21201.

Received for publication 26 June 1989 and in revised form $25 \mathrm{Au}$ gust 1989

1. Abbreviations used in this paper: ASC, antibody-secreting cell, BHIA, brain-heart infusion agar, CFA, colonization factor antigen; $\mathrm{CHO}$, Chinese hamster ovary; CT, cholera toxin; ETEC, enterotoxigenic Escherichia coli; FA, fluid accumulation; NAG-ST, heat-stable enterotoxin produced by strains of non-O1 $V$. cholerae; OMP, outer membrane protein; RBC, red blood cell; RITARD, removable intestinal tie-adult rabbit diarrhea; $V$. cholerae $\mathrm{O} 1, \mathrm{O}$ group 1 Vibrio cholerae.

J. Clin. Invest.

(c) The American Society for Clinical Investigation, Inc.

0021-9738/90/03/0697/09 \$2.00

Volume 85, March 1990, 697-705 than 1 (non-O1 or nonagglutinable [NAG] $V$. cholerae) in human disease is much less clear. Non-O1 strains have been implicated in outbreaks of foodborne disease $(6,7)$, isolated from as many as $13 \%$ of patients with cholera-like disease during cholera epidemics (8-10), and identified in stool samples from patients with gastroenteritis in Asia (11, 12), Africa (13), Europe (14), Australia, and North $(15,16)$ and South (17) America. They are also ubiquitous in estuarine environments (including bays and estuaries of the U. S. Gulf, Atlantic, and Pacific coasts) and commonly are isolated from shellfish: a study conducted by the U. S. Food and Drug Administration found non-O1 $V$. cholerae in up to $37 \%$ of U. S. oyster lots harvested during warm, summer months (18).

Although clinical observations suggest that non-O1 V.cholerae cause diarrhea, the number of reported cases of non-O1 disease in the United States is much less than might be anticipated $(4,19)$, given the amount of shellfish consumed and the frequency with which the organism is present in shellfish. In the absence of clear data to the contrary, it could be hypothesized that non-O1 $\mathrm{V}$. cholerae are simply commensals that do not cause disease. If non-O1 strains do cause illness, the small number of reported cases may be due to differences in host susceptibility, or reflect the need for a high infectious dose (4). Alternatively, perhaps only a minority of strains, carrying specific virulence factors, are able to cause disease.

Proposed virulence factors for non-O1 $V$. cholerae have included toxins similar to cholera toxin $(12,20-22)$, the El Tor (23-25) and Kanagawa (26) hemolysins, a Shiga-like toxin (27), various cell-associated hemagglutinins $(22,28)$, and a 17-amino acid, heat-stable enterotoxin (designated NAG-ST), which closely resembles the heat-stable toxin produced by enterotoxigenic strains of Escherichia coli $(26,29-31)$. It has also been suggested that virulence is dependent on the ability of a non-O1 $V$. cholerae strain to colonize the intestine, as demonstrated in rabbits using the removable intestinal tie-adult rabbit diarrhea (RITARD) model (32). In an effort to determine if non-O1 $V$. cholerae are indeed pathogenic and to investigate the importance of purported virulence factors in disease, we administered three non-O1 strains to a total of 27 volunteers. These are the first such volunteer studies ever conducted with non-O1 $V$. cholerae strains.

\section{Methods}

\section{Characterization of strains}

For these studies three strains of non-O1 $V$. cholerae were employed (Table I): 2076-79 (designated as strain A), isolated from a patient with diarrhea living in Mississippi who had eaten raw oysters (15); A-5 (strain B), isolated from frozen shrimp in Japan (29); and NRT36S (strain C), isolated from a patient with traveler's diarrhea seen at the quarantine station at Narita Airport, Tokyo. Species identity was con- 


\begin{tabular}{|c|c|c|c|}
\hline & \multicolumn{3}{|c|}{ Strains } \\
\hline & A & B & C \\
\hline Laboratory strain number & 2076-79 & A-5 & NRT36S \\
\hline Country isolated & United States & Japan & Japan \\
\hline Source & Stool: patient with diarrhea & Frozen shrimp & Stool: patient with diarrhea \\
\hline Serotype (Smith) & 017 & 031 & 031 \\
\hline \multicolumn{4}{|l|}{ Toxin production } \\
\hline \multicolumn{4}{|l|}{ Tissue culture (cytotoxic response)* } \\
\hline Y-1 adrenal & 16 & 64 & 8 \\
\hline $\mathrm{CHO}$ & 16 & 64 & 8 \\
\hline $\mathrm{CaCo}-2$ & 2 & 4 & 1 \\
\hline \multicolumn{4}{|l|}{ DNA probes } \\
\hline Cholera toxin & - & - & - \\
\hline El Tor hemolysin & + & + & + \\
\hline Kanagawa hemolysin & - & - & - \\
\hline Hemolytic rabbit RBCs & + & + & + \\
\hline Production of Shiga-like toxin (cell lysate) & + & - & - \\
\hline FA index for detection of NAG-ST in infant mice & $0.049^{\ddagger}$ & 0.092 & 0.112 \\
\hline $\begin{array}{l}\text { FA index after neutralization by monoclonal } \\
\text { antibody against NAG-ST }\end{array}$ & - & 0.050 & 0.055 \\
\hline \multicolumn{4}{|l|}{ Hemagglutination/fimbriae/colonization factors } \\
\hline \multicolumn{4}{|l|}{ Hemagglutination* } \\
\hline Human & $\mathbf{0}$ & 8 & 8 \\
\hline Sheep & 4 & 2 & 4 \\
\hline Rabbit & 16 & 64 & 16 \\
\hline Piliation (electron microscopy) & + & - & - \\
\hline DNA probe: $t c p$ A gene & - & - & - \\
\hline \multicolumn{4}{|l|}{ Animal model (RITARD) } \\
\hline Colonization & $5 / 5^{\S}$ & $1 / 4$ & $4 / 4$ \\
\hline Diarrhea & $4 / 5$ & $0 / 4$ & $3 / 4$ \\
\hline Death & $3 / 5$ & $0 / 4$ & $4 / 4$ \\
\hline
\end{tabular}

* Reported as reciprocal titer of highest dilution of culture supernatant that gave a positive response. ${ }^{\ddagger}$ Positive response defined as FA index $\geq 0.090$; values are means of three determinations. ${ }^{\$}$ Number of positive per number animals challenged.

firmed and strains were serotyped by Dr. Harry L. Smith, Vibrio Reference Laboratory, Jefferson Medical College, Philadelphia.

Toxin production. Results of selected assays are shown in Table I. Culture supernatants of the three strains were tested against three tissue culture cell lines: Y-1 adrenal, Chinese hamster ovary (CHO), and Caco-2 (33) cells. None of the strains gave a cytotonic response characteristic of cholera toxin in either Y-1 adrenal or CHO cells $(34,35)$. Supernatants did produce a cytotoxic response in all cell lines, with cell rounding and destruction of the cell monolayer.

None of the strains carried the gene for cholera toxin, as determined by DNA colony hybridization (21). All three strains were hemolytic for rabbit red blood cells (RBC) on plates containing $1 \%$ rabbit RBC in Luria agar (36). All had the gene for the El Tor but not the Kanagawa hemolysin $(37,38)$. In studies conducted by Dr. Alison O'Brien, Uniformed Services University of the Health Sciences, Bethesda, MD, a cell-associated Shiga-like toxin (27) was produced by strain A but not by strains $B$ and $C$.

Culture supernatants of strains $B$ and $C$ gave a positive fluid accumulation (FA) response in suckling mice (29). The FA activity of both strains was neutralized by a monoclonal antibody directed against NAG-ST. Culture supernatants were partially purified by sequential ammonium sulfate precipitation, hydroxyl apatite treatment, and ethanol extraction and were assayed for the presence of NAG-ST by competitive ELISA using synthetic NAG-ST as a standard. Superna- tants from strains $B$ and $C$ (but not A) contained nearly $1 \mu \mathrm{g} / \mathrm{ml}$ NAG-ST. On colony blots, strains $B$ and $C$ hybridized with a oligonucleotide probe derived from the amino acid sequence of NAG-ST (Hoge, C. W., O. Sethabutr, P. Echeverria, D. Robertson, and J. G. Morris, Jr. Manuscript submitted for publication). Strain A did not hybridize with this probe.

Hemagglutination/fimbriae/colonization factors. Hemagglutination assays were performed as described by Shehabi et al. (28), using fresh human type $O$, rabbit, and sheep RBC; results are summarized in Table I. The hemagglutination response in each instance was inhibited by the addition of $1 \%$ D-mannose.

Strain A had fimbriae as demonstrated by electron microscopy (Fig. 1). Fimbriae were most prominent when cells were grown on colonization factor antigen (CFA) agar with $66 \mathrm{mM} \mathrm{NaCl}(39,40)$; however, fimbriae were also demonstrable after growth on brain-heart infusion agar (BHIA). Similar attempts to demonstrate fimbriae on strain $B$ or $C$ were unsuccessful. In hybridization studies conducted by Dr. Ronald Taylor, University of Tennessee Health Science Center, Memphis, none of the strains carried the structural gene for the TcpA pilus, the major colonization factor for $V$. cholerae $\mathrm{Ol}$ in humans $(41,42)$.

Animal models. In Spira's RITARD model (32), strains A and C colonized and caused diarrhea (Table I). Strain B colonized only one of four rabbits, and caused no disease. 

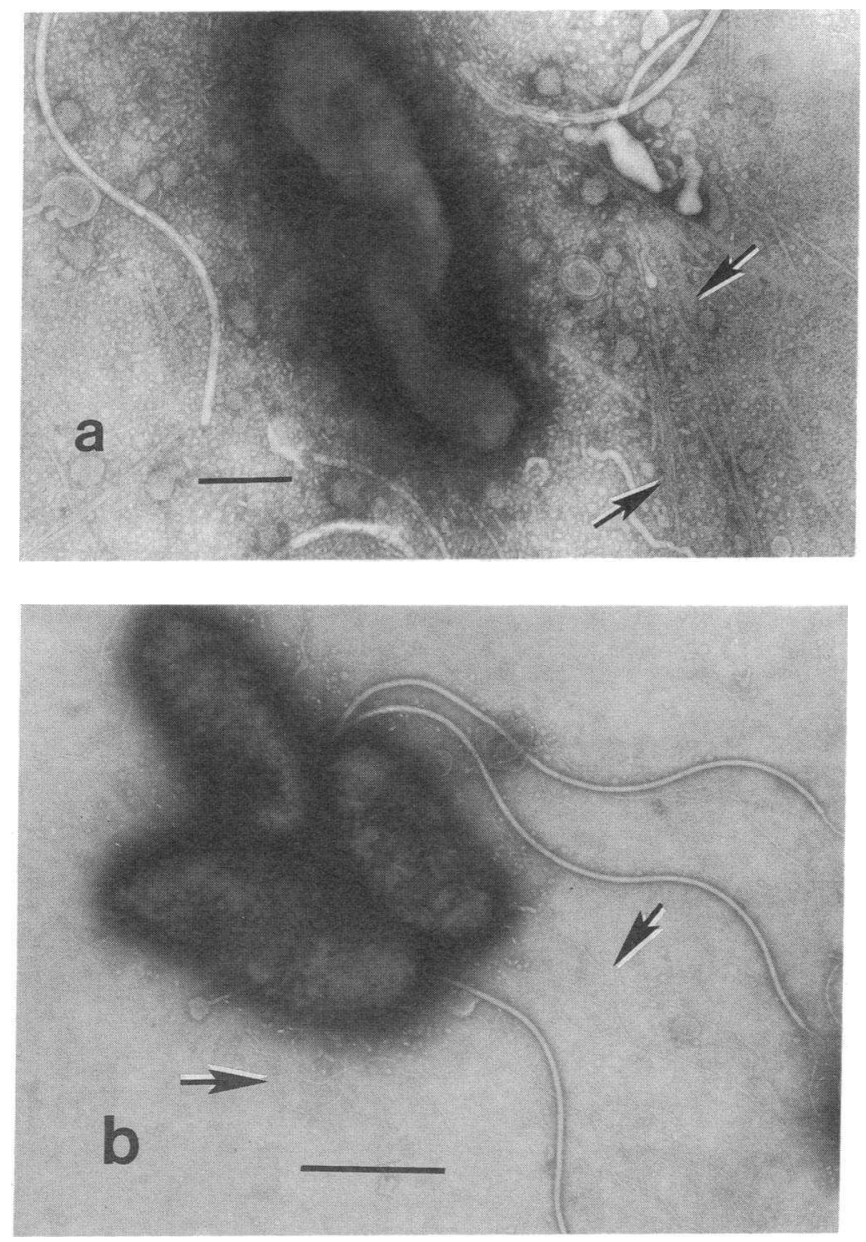

Figure 1. Electron photomicrographs of strain A after growth on (a) CFA and $(b)$ BHIA. Fimbriae are indicated by arrows. Bars: $0.5 \mu \mathrm{m}$; $1 \mu \mathrm{m}$.

\section{Clinical challenge studies}

Strains were administered in sequential studies to healthy community volunteers. Volunteers ( 23 men and 4 women) ranged in age from 18 to $34 \mathrm{yr}$ (mean $24 \mathrm{yr}$ ). None had any underlying disease, or had had any abdominal surgery other than an appendectomy; none had been on any medication for at least $4 \mathrm{wk}$ preceding challenge. All volunteers had a complete physical examination and extensive laboratory evaluation (including complete blood count with indices, electrolytes, liver function tests, blood urea nitrogen and creatinine, blood glucose, rapid plasma reagin, hepatitis B surface antigen, serum pregnancy test, complete urinalysis, and screening for HIV) before being allowed to participate. Volunteers were hospitalized at University Hospital, Baltimore, on the research ward of the Center for Vaccine Development. Detailed informed consent was obtained for all aspects of the study; volunteers were required to pass a written test demonstrating their understanding of the study before being allowed to participate. Studies were approved by the Human Volunteer Research Committee of the University of Maryland School of Medicine.

Non-O1 $V$. cholerae for inocula were grown overnight on BHIA plates at $37^{\circ} \mathrm{C}$, harvested, washed twice, and resuspended in sterile buffered saline ( $\mathrm{pH} 7.2)$ at the desired concentration. In accord with our standard protocol $(37,40,43,44)$, strains were administered to volunteers $1 \mathrm{~min}$ after ingestion of $2 \mathrm{~g}$ of sodium bicarbonate (to neutralize gastric acidity). Symptoms were recorded daily. All stools passed by the volunteers were characterized macroscopically, weighed, screened for the presence of gross and occult blood, and cultured. Volunteers who developed diarrhea were treated aggressively with oral rehydration solution and, if necessary, intravenous fluids. After a 5-7-d period of observation, all volunteers received a 5-d course of tetracycline $(500 \mathrm{mg}$ every $6 \mathrm{~h}$ ) to eliminate further carriage of the organism. Tetracycline was started immediately if volunteers had diarrhea severe enough to require intravenous rehydration.

Stool samples were cultured using direct plating, enrichment, and quantitative techniques. Blood cultures were obtained 1, 6, 24, and 48 h after challenge. Duodenal cultures collected using a string capsule (Enterotest, Hedeco, Palo Alto, CA) (45) were obtained 24 and 48 h after challenge. Non-O1 $V$. cholerae were identified in culture on the basis of characteristic morphology, biochemical tests, and failure to agglutinate in $\mathrm{Ol}$ antisera. Selected diarrheal stool samples were frozen, concentrated by lyophilization, and screened for the presence of NAG-ST in suckling mice and by competitive ELISA.

\section{Assessment of immune response}

Serum samples were collected on days $0,7,14,21$, and 28 and screened by enzyme-linked immunosorbent assay (ELISA) for specific antibodies to NAG-ST; outer membrane proteins (OMP) and lipopolysaccharide (LPS) from the homologous non-O1 $V$. cholerae challenge strain; and homologous non-O1 $V$. cholerae whole-cell lysates. In some cases jejunal fluid samples were collected by intestinal intubation on day 0 and 8 , and screened for the presence of specific secretory IgA antibody. OMP were prepared by the method of Johnston et al. (46), using modifications as described by Richardson and Parker (47). LPS was extracted using a modification of the standard Westphal and Jann procedure (48). For OMP, LPS, and whole-cell lysates, serial twofold dilutions of each sample were tested, and the antibody titer was defined as the last dilution giving a corrected OD reading of $\geq 0.15$; persons showing a fourfold or greater rise in titer were considered to have a positive response. Serum samples were also screened for the presence of vibriocidal antibodies (49) to the homologous strain.

Volunteers receiving strain $C$ were screened for the presence of antibody-secreting cells (ASC) in blood samples collected on days 0,7 , and 14 , using an ELISA to identify specific IgG and IgA antibodies produced in vitro by peripheral blood lymphocytes (50). Briefly, 96well polyvinyl microtiter ELISA plates were coated with our OMP preparation at a concentration of $2 \mu \mathrm{g} / \mathrm{ml}$. Plates were washed and blocked with $0.05 \%$ bovine serum albumin, and $100 \mu \mathrm{l}\left(10^{6}\right)$ of peripheral blood lymphocytes obtained by centrifugation of heparinized venous blood on Ficoll-Paque (Pharmacia, Uppsala, Sweden) were added to replicate wells on the plates. After incubation at $37^{\circ} \mathrm{C}$ for 16 $\mathrm{h}$, appropriate enzyme-conjugated class-specific antisera and substrate were added (50), and the amount of OMP-specific antibody produced was expressed as an OD (absorbance at $405 \mathrm{~nm}$ ). A positive response was defined as an increase in $\mathrm{OD}$ of $>2 \mathrm{SD}$ from the mean of values obtained with prechallenge (day 0 ) lymphocytes.

\section{Results}

For our volunteer studies we initially selected strain A: it was a clinical isolate, gave a strong positive response in our RITARD model, and carried a number of purported virulence factors. As summarized in Table II, strain A was administered to volunteers in sequential studies at doses of $10^{6}, 10^{7}, 10^{8}$, and $10^{9}$ CFU. Of the 13 volunteers, 10 excreted the organism in their stool or had positive duodenal string capsule cultures (Table III). Stool excretion persisted for days, with six volunteers still culture-positive for non-O1 $V$. cholerae when therapy with tetracycline was initiated. However, none had diarrhea or any other complaint. Eight volunteers had a serologic response to the organism, as evidenced by a fourfold rise in titer to homologous OMP or LPS preparations (Table IV). No correlation 
Table II. Clinical Results: Volunteer Studies with Non-01 Vibrio cholerae

\begin{tabular}{cccccc}
\hline & & \multicolumn{3}{c}{ No. of volunteers with: } & \\
\cline { 3 - 4 } $\begin{array}{c}\text { Inoculum } \\
\text { size }\end{array}$ & $\begin{array}{c}\text { No. of } \\
\text { volunteers }\end{array}$ & Diarrhea & Fever & $\begin{array}{c}\text { Abdominal } \\
\text { pain }\end{array}$ & $\begin{array}{c}\text { Diarrheal stool } \\
\text { volumes }\end{array}$ \\
\hline & & & & & $m$ \\
Strain A & & & & & \\
$10^{6}$ & 4 & 0 & 0 & 0 & - \\
$10^{7}$ & 1 & 0 & 0 & 0 & - \\
$10^{8}$ & 4 & 0 & 0 & 0 & - \\
$10^{9}$ & 4 & 0 & 0 & 0 & - \\
Strain B & & & & & - \\
$10^{7}$ & 2 & 0 & 0 & 1 & - \\
$10^{9}$ & 2 & 0 & 0 & 1 & - \\
Strain C & & & & & - \\
$10^{5}$ & 2 & 0 & 0 & 0 & $5,397,140$ \\
$10^{6}$ & 3 & 2 & 0 & 2 & 589 \\
$10^{7}$ & 2 & 1 & 0 & 0 & $2,091,276,253$ \\
$10^{9}$ & 3 & 3 & 0 & 3 & \\
\hline
\end{tabular}

was seen between initial antibody titer and subsequent excretion of non-O1 $V$. cholerae.

In evaluating our data after this initial set of studies we noted that strain A did not produce NAG-ST, leading to the hypothesis that NAG-ST was an important virulence factor for non-O1 $V$. cholerae. To test this hypothesis, we obtained strain $B$, an environmental strain that was used in one of the initial descriptions of NAG-ST (29). This strain was administered to volunteers in sequential studies at doses of $10^{7}$ and $10^{9} \mathrm{CFU}$. None of the volunteers had a positive duodenal string capsule or stool culture (Table III). None had diarrhea, although two complained of mild abdominal cramps. None had antibodies directed against NAG-ST; three of four had a serologic response to an OMP preparation from the homologous strain.

These results led to the hypothesis that virulence was dependent both on the ability of a strain to colonize the intestine and on the elaboration of a toxin such as NAG-ST. To test this hypothesis, we obtained strain $\mathrm{C}$, a clinical isolate that produced high levels of NAG-ST and colonized and caused disease in our rabbit model. Strain $\mathrm{C}$ was initially administered at a dose of $10^{7} \mathrm{CFU}$. One of two volunteers receiving this dose had diarrhea, with a total stool volume of $242 \mathrm{ml}$. When we administered $10^{9} \mathrm{CFU}$, all three volunteers developed diarrhea and abdominal cramps, with diarrheal stool volumes of 2,091, 276 , and $253 \mathrm{ml}$, respectively. The frequency of illness differed significantly when persons receiving $10^{9} \mathrm{CFU}$ of strain $\mathrm{C}$ were compared with those receiving $10^{9} \mathrm{CFU}$ of strain A $(P=0.03$, Fisher's exact test).

In an effort to better define the infectious dose for this strain, we then administered strain $C$ to volunteers in doses of $10^{5}$ and $10^{6}$. Persons receiving $10^{5} \mathrm{CFU}$ were asymptomatic. One of three volunteers receiving $10^{6} \mathrm{CFU}$ had minimal diarrhea ( $140 \mathrm{ml})$, without abdominal cramps (Table II); a second complained of abdominal cramps, but had no diarrhea. The third volunteer receiving $10^{6} \mathrm{CFU}$ had a total diarrheal stool volume of $5,397 \mathrm{ml}$. This volunteer had $1,970 \mathrm{ml}$ of diarrhea and over $600 \mathrm{ml}$ of emesis during the first $4 \mathrm{~h}$ of illness. Intravenous rehydration was initiated at this point, and the volun- teer was started on therapy with tetracycline; during the next $22 \mathrm{~h}$ she had an additional $3,420 \mathrm{ml}$ of diarrhea. If uncorrected, fluid losses associated with her diarrhea would have represented a fluid deficit of $\sim 9 \%$ of her admission weight. Diarrheal stools assumed the characteristic "rice water" appearance seen in severe cases of cholera within $3 \mathrm{~h}$ of onset of illness.

Stool samples collected 4, 7, and $12.5 \mathrm{~h}$ after onset of illness in the volunteer who had $5,397 \mathrm{ml}$ of diarrhea were screened for the presence of NAG-ST. At a $5 \times$ concentration, FA ratios for these samples were $0.070,0.057$, and 0.094 , respectively (average of at least two determinations). FA activity was unaffected by heat $\left(100^{\circ} \mathrm{C}, 10 \mathrm{~min}\right)$ but was neutralized by a monoclonal antibody directed against NAG-ST. By competitive ELISA, NAG-ST could be clearly demonstrated in the 12.5-h sample. In keeping with our inclusion criteria for vol-

Table III. Culture Results: Volunteer Studies with Non-01 Vibrio cholerae

\begin{tabular}{|c|c|c|c|c|c|c|c|c|c|c|c|}
\hline \multirow{2}{*}{$\begin{array}{l}\text { Inoculum } \\
\text { size }\end{array}$} & \multirow{2}{*}{$\begin{array}{c}\text { Patient } \\
\text { No. }\end{array}$} & \multicolumn{2}{|c|}{$\begin{array}{l}\text { String } \\
\text { (day) }^{*}\end{array}$} & \multicolumn{7}{|c|}{ Stool (day) } & \multirow[b]{2}{*}{ Peak } \\
\hline & & 1 & 2 & 1 & 2 & 3 & 4 & 5 & 6 & 7 & \\
\hline
\end{tabular}

Strain A

\begin{tabular}{|c|c|c|c|c|c|c|c|c|c|c|c|}
\hline \multirow[t]{4}{*}{$10^{6}$} & 1 & - & & - & - & - & - & - & & & \\
\hline & 2 & - & - & - & + & + & - & + & & & $7 \times 10^{2}$ \\
\hline & .3 & - & & - & - & - & - & - & & & \\
\hline & 4 & - & & - & + & + & - & + & & & \\
\hline $10^{7}$ & 5 & - & - & - & - & - & - & - & - & - & \\
\hline \multirow[t]{4}{*}{$10^{8}$} & 6 & + & - & - & - & - & - & - & - & - & \\
\hline & 7 & - & & - & + & + & + & + & + & + & $3 \times 10^{3}$ \\
\hline & 8 & + & + & + & + & + & + & + & + & + & $2 \times 10^{2}$ \\
\hline & 9 & & & + & - & + & - & - & - & - & $6 \times 10^{2}$ \\
\hline \multirow[t]{4}{*}{$10^{9}$} & 10 & + & + & - & - & - & - & - & & & \\
\hline & 11 & - & & - & + & + & + & - & & & $6 \times 10^{6}$ \\
\hline & 12 & - & & - & + & - & - & + & & & $5 \times 10^{2}$ \\
\hline & 13 & & & - & + & + & + & + & & & $9 \times 10^{4}$ \\
\hline
\end{tabular}

Strain B

$10^{7} \quad 1 \quad-\quad-\quad-\quad--$

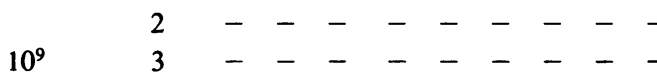

$4-------$

Strain C

$10^{5}$

$10^{6}$

$10^{7}$

$10^{9}$

$$
\begin{aligned}
& +----- \\
& -+++- \\
& +8 \quad 2 \times 10^{6} \\
& -\quad-\quad--- \\
& ------ \\
& \begin{array}{r}
++++-\quad-9 \times 10^{2} \\
-++-\quad 4 \times 10^{3}
\end{array} \\
& +++-+ \\
& >3 \times 10^{8} \\
& 6 \times 10^{4} \\
& 4 \times 10^{6}
\end{aligned}
$$

* Duodenal string capsule culture: results recorded only for strings having a $\mathrm{pH} \geq 5.0$.

‡ CFU per gram of stool; highest value obtained reported.

$\S$ Tetracycline started $13 \mathrm{~h}$ after challenge. 


\begin{tabular}{|c|c|c|c|c|c|c|c|c|c|c|c|c|}
\hline \multirow[b]{3}{*}{ Inoculum size } & \multicolumn{8}{|c|}{ Serologic response (vibriocidal and ELISA) } & & & & \\
\hline & \multirow[b]{2}{*}{ No. tested } & \multirow[b]{2}{*}{$\mathrm{Vib}^{\ddagger}$} & \multicolumn{2}{|c|}{ OMP } & \multicolumn{2}{|c|}{ LPS } & \multicolumn{2}{|c|}{ Whole cell } & \multicolumn{4}{|c|}{ Jejunal secretory IgA* (ELISA) } \\
\hline & & & IgG & IgA & IgG & IgA & IgG & IgA & No. tested & OMP & LPS & Whole cell \\
\hline \multicolumn{13}{|l|}{ Strain A } \\
\hline $10^{6}$ & 4 & 0 & 1 & 2 & 0 & 0 & 0 & 0 & 4 & 0 & 0 & 0 \\
\hline $10^{7}$ & 1 & 0 & 0 & 1 & 0 & 0 & 0 & 0 & 0 & - & - & - \\
\hline $10^{8}$ & 4 & 0 & 0 & 1 & 0 & 1 & 0 & 0 & 3 & 0 & 0 & 0 \\
\hline $10^{9}$ & 4 & 0 & 0 & 1 & 1 & 1 & 1 & 0 & 3 & 0 & 0 & 0 \\
\hline \multicolumn{13}{|l|}{ Strain B } \\
\hline $10^{7}$ & 2 & 0 & 2 & 2 & 1 & 0 & 1 & 1 & 2 & 0 & 0 & 0 \\
\hline $10^{9}$ & 2 & 0 & 1 & 1 & 0 & 0 & 0 & 0 & 1 & 0 & 1 & 0 \\
\hline \multicolumn{13}{|l|}{ Strain C } \\
\hline $10^{5}$ & 2 & 0 & 0 & 0 & 1 & 0 & 0 & 0 & 2 & 0 & 0 & 0 \\
\hline $10^{6}$ & 3 & 0 & 1 & 1 & 2 & 1 & 1 & 0 & 1 & 1 & 1 & 0 \\
\hline $10^{7}$ & 2 & 0 & 0 & 1 & 0 & 1 & 1 & 0 & 0 & - & - & - \\
\hline $10^{9}$ & 3 & 0 & 1 & 2 & 3 & 2 & 0 & 2 & 0 & - & - & - \\
\hline
\end{tabular}

* Jejunal fluid samples not available for all volunteers. ${ }^{*}$ Vib, vibriocidal assay: homologous strain.

unteers, this volunteer was in excellent health with no underlying illnesses, had had no abdominal surgery, and had taken no medications in the 4 wk preceding the study; she did report having taken several courses of tetracycline during the preceeding year for acne.

The median incubation period for illness with strain $\mathrm{C}$ was $10 \mathrm{~h}$ (range 5.5-96 h); there was no obvious association between incubation period and inoculum size. None of the volunteers were febrile, and none had grossly bloody or hemepositive diarrhea. Diarrhea tended to be short-lived, with a median duration of $21 \mathrm{~h}$ (range 3.5-48 h). There was a suggestion that diarrhea was more likély to result with higher bacterial inocula $\left(P=0.06, \chi^{2}\right.$ test for trend).

There was no clear difference in initial antibody titers when persons who became ill were compared with other persons receiving strain $\mathbf{C}$ or with persons receiving strains $\mathrm{A}$ or $\mathrm{B}$. With the exception of one person receiving $10^{5} \mathrm{CFU}$, all volunteers receiving strain $C$ showed a serum IgG or IgA response to LPS, OMP, or whole-cell lysates. None of the volunteers receiving strain $C$ had antibodies to NAG-ST. The eight volunteers receiving $\geq 10^{6} \mathrm{CFU}$ of strain $\mathrm{C}$ were screened for the presence of lymphocytes secreting specific anti-OMP antibody (ASC assay). In samples obtained on day 7, six volunteers (five of whom developed diarrhea) had circulating lymphocytes that produced IgA directed against homologous OMP; this response had returned to baseline levels by day 14 . Only three of the six with a positive ASC response had a rise in anti-OMP IgA antibody titer by ELISA.

\section{Discussion}

Our data clearly demonstrate that non-O1 $V$. cholerae can cause diarrheal disease in otherwise healthy persons. The clinical syndrome seen among persons receiving strain $C$ (short incubation period, frequent and often severe abdominal cramps, short duration of illness) was very similar to that described in non-O1 V. cholerae-associated foodborne disease outbreaks. In a foodborne outbreak reported from Australia the mean incubation period was $11.5 \mathrm{~h}$ (range 5.25-37.5 h); severe abdominal cramps were reported, with diarrhea lasting 18-24 h (6). In a Czechoslovakian outbreak the incubation period was estimated to be $20-30 \mathrm{~h}$, with symptoms resolving in the majority of cases in $<24 \mathrm{~h}(7)$. In contrast, U. S. studies based solely on reported cases have tended to describe a more severe clinical syndrome. In one study of sporadic cases of non-O1 $V$. cholerae gastroenteritis reported to the Centers for Disease Control (15), median duration of illness was $6.4 \mathrm{~d}$, with 7 of 14 patients requiring hospitalization. In this same study a quarter of patients reported bloody diarrhea; none of our volunteers had either grossly bloody or heme-positive stools. Bacteremia due to non-O1 $V$. cholerae has also been described, with reported mortality rates exceeding $60 \%$ (51). None of our volunteers were bacteremic; case reports suggest that bacteremia is limited primarily to persons who are immunocompromised or have underlying liver disease (51).

While the illness that we observed was generally mild, two volunteers had over 2 liters of diarrhea, including one with a stool volume of $5,397 \mathrm{ml}$. In this latter case therapy with tetracycline was started shortly after onset of illness; this volunteer may have had even more severe diarrhea had antibiotic therapy not been so prompt (52). Fluid deficits totaling $12 \%$ or more of body weight in cholera patients are usually fatal in the absence of appropriate rehydration therapy (53). The purge experienced by our volunteer did not reach this value, but was clearly equivalent to that seen in severe cases of cholera (cholera gravis). There was no obvious explanation for this volunteer having had such severe disease: she was in excellent health, with no underlying illnesses. There are anecdotal data (54) suggesting that use of $\beta$-lactam antibiotics increases susceptibility to infection with Aeromonas hydrophilia, another member of the Vibrionaceae. While our volunteer had taken no medications for $4 \mathrm{wk}$ preceding the non-Ol $\mathrm{V}$. cholerae challenge, her prior use of tetracycline may have in some way affected her normal gastrointestinal flora and, in turn, in- 
creased her susceptibility to illness. It should be noted, however, that $V$. cholerae $\mathrm{O} 1$ strains often produce a similar wide range of clinical response among volunteers (Levine, M. M., personal communication).

Persons recovering from cholera generally develop high vibriocidal antibody titers, together with antibodies directed against cholera toxin (49); half will show an immune response to outer membrane proteins of the homologous strain (55). Our non-O1 strains did not elicit a vibriocidal response, in agreement with observations made during a small outbreak of non-O1 V. cholerae gastroenteritis in Florida (Morris, J. G., unpublished data). Our failure to show an immune response to NAG-ST was also not unexpected, because heat-stable enterotoxin produced by enterotoxigenic $E$. coli (ETEC) is generally regarded as nonimmunogenic or poorly immunogenic (56, 57). The majority of volunteers did show a rise in titer to homologous LPS, OMP, or whole-cell lysates, with an even higher number of responders identified by our more sensitive assay for circulating $\operatorname{ASC}(50,58)$. However, these responses showed no clear correlation with illness or colonization, suggesting that an immune response was elicited by the simple presence of the organism (i.e., the inoculum) in the gastrointestinal tract. Similar observations have been made with $V$. cholerae $\mathrm{O} 1$, with killed $\mathrm{O} 1$ strains eliciting an immune response after oral administration (59). The antibodies directed against killed $V$. cholerae $\mathrm{O} 1$ provide some protection against subsequent disease $(59,60)$. In the absence of rechallenge studies, we can not say whether the antibodies we detected would be similarly protective.

Strains $A$ and $C$ were present in stool samples from volunteers for at least $5 \mathrm{~d}$ after bacterial challenge and were recovered from duodenal string capsule cultures. Strain B was administered in comparable doses $\left(10^{9} \mathrm{CFU}\right)$ but was not recovered from stool or duodenal cultures. These results strongly suggest that strains $A$ and $C$ were able to colonize our volunteers, whereas strain B (an environmental strain) was not. This parallels observations made in rabbits: strains from clinical sources were able to colonize the rabbit intestine in the RITARD model (with resulting diarrhea), whereas environmental isolates were not (32). Fimbriae play a critical role in gastrointestinal colonization by ETEC (ETEC) and $V$. cholerae $\mathrm{O} 1$ $(41,42,61)$. Strain A did produce fimbriae, although not the TcpA fimbriae that appear to be essential for $V$. cholerae $\mathrm{O} 1$ colonization (42). We were unable to demonstrate fimbriae on strain $\mathrm{C}$, in agreement with studies that have reported that only a small percentage of clinical non-O1 $\mathrm{V}$. cholerae isolates are fimbriated (62). It is possible that this failure to see fimbriae is technical: optimal conditions for in vitro expression of fimbriae by non-O1 $V$. cholerae may simply not have been used. Alternatively, strains may have nonfimbrial adhesive factors, similar to those described for some $E$. coli $(63,64)$.

Although both strains $\mathrm{A}$ and $\mathrm{C}$ colonized volunteers, only strain $C$ caused disease, suggesting that colonization alone was not sufficient to cause human illness. Based on experience with other enteric pathogens, including ETEC and $V$. cholerae $\mathrm{O} 1(37,42,61)$, we would hypothesize that virulence of non-O1 $V$. cholerae is dependent both on the ability of a strain to colonize the intestine and on production of an appropriate toxin. Several investigators have noted that non-O1 strains are cytotoxic for tissue culture cell lines $(65,66)$. However, the factors or toxins responsible for cytotoxicity do not appear to be directly associated with human disease: strain $\mathrm{C}$, which caused illness, was the least cytotoxic of the three challenge strains in the cell lines tested. Similarly, our data do not support the hypothesis that Shiga-like toxin (27) or the El Tor hemolysin (23-25) are important factors in determining virulence for humans, in that both were produced by strain $A$, which colonized volunteers but did not cause illness. In studies with a cholera toxin (CT)-negative $V$. cholerae 01 strain, deletion of the hemolysin gene did not affect the reactogenicity of the parent strain (37), providing further evidence that the hemolysin is not a critical virulence factor for humans.

Some non-O1 $V$. cholerae strains produce CT or a CT-like toxin $(12,20-22)$, with studies of hospitalized patients in Bangladesh suggesting that persons infected with CT-positive strains have more severe symptoms than those infected with strains that do not produce CT (12). We did not include CTproducing strains in this study, and consequently cannot comment on the possible role of CT in virulence. Similarly, none of our strains carried the thermostable direct (or Kanagawa) hemolysin, a marker for virulence for $V$. parahaemolyticus (4) that has been identified in $10 \%$ of clinical non-O1 $\mathrm{V}$. cholerae strains isolated in Japan (26).

Our data do suggest that NAG-ST plays a role in the pathogenesis of non-O1 $V$. cholerae gastroenteritis. A family of low molecular weight heat-stable enterotoxins produced by enteric pathogens is now recognized (31): this includes human and porcine heat-stable enterotoxins (STh and STp), elaborated by ETEC; Y-ST, produced by Yersinia enterocolitica (67); NAG$\mathrm{ST}$, produced by non-O1 $\mathrm{V}$. cholerae; and Mimicus-ST, produced by $V$. mimicus. These compounds all show a FA response in suckling mice, and have almost identical amino acid sequences (Fig. 2). The role of STh and STp in production of human and porcine diarrheal illness, respectively, is well established $(57,68,69)$. The importance of heat-stable enterotoxin produced by other bacterial species is less clear. We would hypothesize that NAG-ST is a virulence factor for some non-O1 $V$. cholerae strains, based on the observation that illness resulted only after administration of a strain that produced NAG-ST. Identification of NAG-ST in stool samples from one of our volunteers suggests that NAG-ST is produced in vivo, and provides further evidence for its etiologic role in diarrheal disease. However, we cannot be certain that strain $\mathbf{C}$ does not carry other, as yet unidentified, toxins or virulence factors. Demonstration that NAG-ST is necessary for production of diarrhea will require construction and testing of

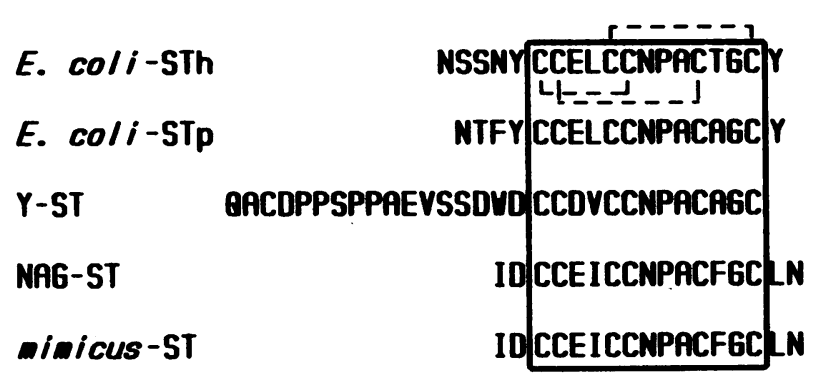

Figure 2. Amino acid sequences of related heat-stable enterotoxins: STh and STp, human and porcine heat-stable enterotoxins; Y-ST, Yersinia enterocolitica-produced heat-stable enterotoxin; NAG-ST; mimicus-ST, V. mimicus-produced enterotoxin (data from Yamasaki et al. [31]). Box encloses regions showing a high degree of homology; intramolecular disulfide bonds are indicated by dashed lines. 
isogenic, heat-stable enterotoxin-negative mutants of strain C (70).

NAG-ST is produced by up to $55 \%$ of non-O1 $V$. cholerae strains isolated from clinical specimens in Japan (29). However, the frequency of heat-stable enterotoxin production varies from one geographic area to another: utilizing an oligonucleotide probe for NAG-ST, we have identified the NAG-ST gene in $6 \%$ of a collection of clinical isolates from Thailand, but in no U. S. or Mexican isolates (Hoge, C. W., O. Sethabutr, P. Echeverria, D. Robertson, and J. G. Morris, Jr. Manuscript submitted for publication). A comparable variability in geographic distribution is seen among CT-producing strains. While up to $38 \%$ of clinical non-O1 $V$. cholerae isolates in India and Bangladesh produce CT $(12,22),<5 \%$ of U. S. clinical isolates $(15,21,71)$ and $0 \%$ of clinical isolates from Thailand (72), Mexico (16), and South America (17) have been reported to carry the $C T$ gene. Even if subsequent studies show that heat-stable enterotoxin (and/or CT) are necessary for virulence, there are many non-O1 $\mathrm{V}$. cholerae isolates that do not produce either toxin (including a majority of U. S. clinical isolates). It is possible that these isolates are not pathogens, and were only incidently isolated from persons who had diarrhea; this would be in keeping with our observation that strain A, a CT- and heat-stable enterotoxin-negative U. S. clinical isolate, did not cause human disease. Alternatively, strains may carry as yet unidentified toxins or virulence factors. These factors may be common to all pathogenic strains (including strain C), or, analogous to the heterogeneity seen among diarrheagenic $E$. coli strains (61), there may be a variety of virulence mechanisms involved in the pathogenesis of non-O1 $V$. cholerae gastroenteritis.

\section{Acknowledgments}

Strain A-5 (strain B) was kindly provided by Dr. Toshio Miwatani, Research Institute for Microbial Diseases, Osaka University, Osaka, Japan. We thank Dr. Harry Smith, Vibrio Reference Laboratory, Jefferson Medical College, Philadelphia, for serotyping our challenge strains. Dr. Ronald K. Taylor, Department of Microbiology, University of Tennessee Health Science Center, Memphis, examined the strains for the presence of the tcpA gene; Dr. Alison O'Brien, Department of Microbiology, Uniformed Services University of the Health Sciences, Bethesda, MD, screened the strains for production of Shigalike toxin. Strains were initially screened for the production of NAGST by Dr. Michiko Arita, also of the Research Institute for Microbial Diseases, Osaka. Anita Wright, David Maneval, and Rosanna Lagos, Division of Geographic Medicine, University of Maryland, Baltimore, provided technical assistance in preparation of antigens. The volunteer studies were possible only because of the efforts of physicians, nurses, and laboratory personnel at the Center for Vaccine Development, Baltimore.

These studies were supported by U. S. Public Health Service contract NO1-AI-62528 and U. S. Public Health Service grant 1R22AI28856-01.

\section{References}

1. Smith, H. L., Jr. 1979. Serotyping of non-cholera vibrios. J. Clin Microbiol. 10:85-90.

2. Sakazaki, R., and T. Shimada. 1977. Serovars of Vibrio cholerae. Jpn. J. Med. Sci. Biol. 30:279-282.

3. Siebeling, R. J., L. B. Adams, Z. Yusof, and A. D. Larson. 1984 Antigens and serovar-specific antigens of Vibrio cholerae. In Vibrios in the Environment. R. R. Colwell, editor. John Wiley \& Sons, Inc., New York. 33-58.
4. Morris, J. G. Jr., and R. E. Black. 1985. Cholera and other vibrioses in the United States. N. Engl. J. Med. 312:343-350.

5. Farmer, J. J., F. W. Hickman-Brenner, and M. T. Kelly. 1985. Vibrio. In Manual of Clinical Microbiology. E. H. Lennette, A. Balows, W. J. Hausler, and H. J. Shadomy, editors. American Society for Microbiology, Washington, DC. 282-301.

6. Dakin, W. P. H., D. J. Howell, R. G. A. Sutton, M. F. O'Keefe, and P. Thomas. 1974. Gastroenteritis due to non-agglutinable (noncholera) vibrios. Med. J. Aust. 2:487-490.

7. Aldova, E., K. Laznickova, E. Stepankova, J. Lietava. 1968. Isolation of nonagglutinable vibrios from an enteritis outbreak in Czechoslovakia. J. Infect. Dis. 118:25-31.

8. Dutt, A. K., S. Alwi, and T. Velauthan. 1971. A shellfish-borne cholera outbreak in Malaysia. Trans. R. Soc. Trop. Med. Hyg. 65:815-818.

9. El-Shawi, N., and A. J. Thewaini. 1969. Non-agglutinable vibrios isolated in the 1966 epidemic of cholera in Iraq. Bull. WHO. 40:163-166.

10. Shehabi, A. A., A. B. A. Rajab, and A. A. Shaker. 1980 . Observations on the emergence of non-cholera vibrios during an outbreak of cholera. Jordan Med. J. 14:123-127.

11. McIntyre, O. R., J. C. Feeley, W. B. Greenough, A. S. Benenson, S. I. Hassan, and A. Saad. 1965. Diarrhea caused by non-cholera vibrios. Am. J. Trop. Med. Hyg. 14:412-418.

12. Spira, W. M., R. R. Daniel, Q. S. Ahmed, A. Huq, A. Yusuf, and D. A. Sack. 1978. Clinical features and pathogenicity of O group 1 non-agglutinating Vibrio cholerae and other vibrios isolated from cases of diarrhea in Dacca, Bangladesh. In Symposium on Cholera, Karatsu 1978: Proceedings of the 14th Joint Conference U. S.-Japan Cooperative Medical Science Program Cholera Panel. J. Takeya, and Y. Zinnaka, editors. Toho University, Tokyo. 137-153.

13. Kamal, A. M. 1971. Outbreak of gastroenteritis by non-agglutinable (NAG) vibrios in the Republic of the Sudan. J. Egypt Pub. Health Assoc. 46:125-173.

14. Back, E., A. Ljunggren, and H. Smith, Jr. 1974. Non-cholera vibrios in Sweden. Lancet. 1:723-724.

15. Morris, J. G., R. Wilson, B. R. Davis, I. K. Wachsmuth, C. F. Riddle, H. G. Wathen, R. A. Pollard, and P. A. Blake. 1981. Non-O Group 1 Vibrio cholerae gastroenteritis in the United States. Ann. Intern. Med. 94:656-658.

16. Finch, M. J., J. L. Valdespino, J. G. Wells, G. Perez-Perez, F. Arjona, A. Sepulveda, D. Bessudo, and P. A. Blake. 1987. Non-O1 Vibrio cholerae infections in Cancun, Mexico. Am. J. Trop. Med. Hyg. 36:393-397.

17. Kay, B. A., R. B. Sack, W. M. Spira, H. E. Guerra, C. E. Guerrero, E. Chaparro, A. E. Yi, E. Salazar-Lindo, E. Chea, I. K. Wachsmuth, and B. R. Davis. 1984. Vibrio cholerae non-O1 isolated from five people with diarrhoea in Lima. Lancet. 1:218.

18. Twedt, R. M., Madden, J. M., Hunt, J. M., D. W. Francis, J. T. Peeler, A. P. Duran, W. O. Hebert, S. G. McCay, C. N. Roderick, G. T. Spite, and T. J. Wazenski. 1981. Characterization of Vibrio cholerae isolated from oysters. Appl. Environ. Microbiol. 41:1475-1478.

19. Hoge, C. W., D. Watsky, R. N. Peeler, J. P. Libonati, E. Israel, and J. G. Morris, Jr. 1989. Epidemiology and spectrum of vibrio infections in a Chesapeake Bay community. J. Infect. Dis. 160:985-993.

20. Yamamoto, K., Y. Takeda, T. Miwatani, and J. P. Craig. 1983. Evidence that a non-O1 Vibrio cholerae produces enterotoxin that is similar but not identical to cholera enterotoxin. Infect. Immun. 41:896-901.

21. Kaper, J. B., J. P. Nataro, N. C. Roberts, R. J. Siebeling, and H. B. Bradford. 1986. Molecular epidemiology of non-O1 Vibrio cholerae and Vibrio mimicus in the U. S. Gulf Coast region. J. Clin. Microbiol. 23:652-654.

22. Datta-Roy, K., K. Banerjee, S. P. De, and A. C. Ghose. 1986. Comparative study of expression of hemagglutinins, hemolysins, and enterotoxins by clinical and environmental isolates of non-O1 Vibrio cholerae in relation to their enteropathogenicity. Appl. Environ. Microbiol. 52:875-879. 
23. Ichinose, Y., K. Yamamoto, N. Nakasone, M. J. Tanabe, T. Takeda, T. Miwatani, and M. Iwanaga. 1987. Enterotoxicity of El Tor-like hemolysin of non-O1 Vibrio cholerae. Infect. Immun. 55:1090-1093.

24. McCardell, B. A., J. M. Madden, and D. B. Shah. 1985. Isolation and characterization of a cytolysin produced by Vibrio cholerae serogroup non-O1. Can. J. Microbiol. 31:711-720.

25. Yamamoto, K., Y. Ichinose, N. Nakasone, M. Tanabe, M. Nagahama, J. Sakurai, and M. Iwanaga. 1986. Identify of hemolysins produced by Vibrio cholerae non-O1 and $V$. cholerae $\mathrm{O} 1$, biotype $\mathrm{El}$ Tor. Infect. Immun. 51:927-931.

26. Honda, T., M. Arita, T. Takeda, M. Yoh, and T. Miwatani. 1985. Non-O1 Vibrio cholerae produces two newly identified toxins related to Vibrio parahaemolyticus hemolysin and Escherichia coli heat-stable enterotoxin. Lancet. 2:163-164.

27. O'Brien, A. D., M. E. Chen, R. K. Holmes, J. B. Kaper, and M. M. Levine. 1984. Environmental and human isolates of Vibrio cholerae and Vibrio parahaemolyticus produce a Shigella dysenteriae 1 (Shiga-like) cytotoxin. Lancet. 1:77-78.

28. Shehabi, A. A., H. Drexler, and S. H. Richardson. 1986. Virulence mechanisms associated with clinical isolates of non-O1 Vibrio cholerae. Zentralol. Bakteriol. Mikrobiol. Hyg. Ser. A261:232-239.

29. Arita, M., T. Takeda, T. Honda, and T. Miwatani. 1986. Purification and characterization of Vibrio cholerae non-O1 heat-stable enterotoxin. Infect. Immun. 52:45-49.

30. Takeo, T., Y. Shimonishi, M. Kobayashi, O. Nishimura, M. Arita, T. Takeda, T. Honda, and T. Miwatani. 1985. Amino acid sequence of heat stable enterotoxin produced by Vibrio cholerae non-O1. FEBS (Fed. Eur. Biochem. Soc.) Lett. 193:250-254.

31. Yamasaki, S., H. Ito, T. Hirayama, Y. Takeda, and Y. Shimonishi. 1988. Effects of the activity of amino acid replacements at positions 12,13 and 14 of heat-stable enterotoxin (STh) by chemical synthesis. In Proceedings of the 24th U. S.-Japan Cooperative Medical Science Program Cholera and Related Diarrheal Diseases Panel, Tokyo, November 13-16, 1988. p. 42.

32. Spira, W. M., P. J. Fedorka-Cray, P. Pettebone. 1983. Colonization of the rabbit small intestine by clinical and environmental isolates of non-O1 Vibrio cholerae and Vibrio mimicus. Infect. Immun. 41:1175-1183.

33. Pinto, M., S. Robine-Leon, M.-D. Appay, M. Kedinger, N. Triadou, E. Dussaulx, B. Lacroix, P. Simon-Assmann, K. Haffen, J. Fogh, A. Zweibaum. 1983. Enterocyte-like differentiation and polarization of the human colon carcinoma cell line Caco-2 in culture. Biol. Cell. 47:323-330.

34. Donta, S. H., H. Moon, and S. Whipp. 1974. Detection of heat labile Escherichia coli enterotoxin with the use of adrenal cells in tissue culture. Science (Wash. DC). 183:334-336.

35. Gurrant, R. L., L. L. Brunton, T. C. Schnatman, L. I. Rebhun, and A. G. Gilman. 1974. Cyclic adenosine monophosphate and alterations of Chinese hamster ovary cell morphology: a rapid, sensitive in vitro assay for the enterotoxins of Vibrio cholerae and Escherichia coli. Infect. Immun. 10:320-327.

36. Wright, A. C., J. G. Morris, Jr., D. R. Maneval, K. Richardson, and J. B. Kaper. 1985. Cloning of the cytotoxin/hemolysin gene of Vibrio vulnificus. Infect. Immun. 50:922-924.

37. Levine, M. M., J. B. Kaper, D. Herrington, G. Losonsky, J. G. Morris, Jr., M. L. Clements, R. E. Black, B. Tall, and R. Hall. 1988. Volunteer studies of deletion mutants of Vibrio cholerae $\mathrm{Ol}$ prepared by recombinant techniques. Infect. Immun. 56:161-167.

38. Nishibuchi, M., M. Ishibashi, Y. Takeda, and J. B. Kaper 1985. Detection of the thermostable direct hemolysin gene and related DNA sequences in Vibrio parahaemolyticus and other Vibrio species by the DNA colony hybridization test. Infect. Immun. 49:481-486.

39. Hall, R. H., P. A. Vial, J. B. Kaper, J. J. Mekalanos, and M. M, Levine. 1988. Morphological studies on fimbriae expressed by Vibrio cholerae O1. Microb. Pathogen. 4:257-265.

40. Levine, M. M., P. Ristaino, G. Marley, C. Smyth, S. Knutton, E. Boedeker, R. Black, C. Young, M. L. Clements, C. Cheney, and R.
Patnaik. 1984. Coli surface antigens 1 and 3 of colonization factor antigen II-positive enterotoxigenic Escherichia coli: morphology, purification, and immune responses in humans. Infect. Immun. 44:409420.

41. Taylor, R. K., V. L. Miller, D. B. Furlong, J. J. Mekalanos. 1987. Use of phoA gene fusions to identify a pilus colonization factor coordinately regulated with cholera toxin. Proc. Natl. Acad. Sci. USA. 84:2833.

42. Herrington, D. A., R. H. Hall, G. Losonsky, J. J. Mekalanos, R. K. Taylor, and M. M. Levine. 1988. Toxin, toxin-coregulated pili, and the tox $\mathrm{R}$ regulon are essential for Vibrio cholerae pathogenesis in humans. J. Exp. Med. 168:1487-1492.

43. Levine, M. M., R. E. Black, M. L. Clements, C. Lanata, S. Sears, T. Honda, C. R. Young, and R. A. Finklestein. 1984. Evaluation in humans of attenuated Vibrio cholerae El Tor Ogawa strain Texas Star-SR as a live oral vaccine. Infect. Immun. 43:515-522.

44. Levine, M. M., D. R. Nalin, D. L. Hoover, E. J. Bergquist, R. B. Hornick, and C. R. Young. 1979. Immunity to enterotoxigenic Escherichia coli. Infect. Immun 23:729-736.

45. Benavente, L., E. Gotuzzo, J. Guerra, O. Grados, H. Guerra, and N. Bravo. 1984. Diagnosis of typhoid fever using a string capsule device. Trans. R. Soc. Trop. Med. Hyg. 78:404-406.

46. Johnston, K. H., K. K. Holmes, and E. C. Gotschlich. 1976. The serologic classification of Neisseria gonorrhoeae. 1. Isolation of the outer membrane complex responsible for serotype specificity. $J$. Exp. Med. 143:741-758.

47. Richardson, K., and C. D. Parker. 1985. Identification and characterization of Vibrio cholerae surface proteins by radioiodination. Infect. Immun. 48:87-93.

48. Westphal, O., and K. Jann. 1965. Bacterial lipopolysaccharides. Extraction with phenol-water and further applications of the procedure. Methods Carbohydr. Chem. 5:83-91.

49. Clements, M. L., M. M. Levine, C. R. Young, R. E. Black, Y. L. Lim, R. M. Robins-Browne, and J. P. Craig. 1982. Magnitude, kinetics, and duration of vibriocidal antibody responses in North Americans after ingestion of Vibrio cholerae. J. Infect. Dis. 145:465-473.

50. Forrest, B. D. 1988. Identification of an intestinal immune response using peripheral blood lymphocytes. Lancet. 1:81-83.

51. Safrin, S., J. G. Morris, Jr., M. Adams, V. Pons, R. Jacobs, and J. E. Conte, Jr. 1988. Non-O1 Vibrio cholerae bacteremia: a case report and review. Rev. Infect. Dis. 10:1012-1017.

52. Wallace, C. K., P. N. Anderson, T. C. Brown, S. R. Khanra, G. W. Lewis, N. F. Pierce, S. N. Sanyal, G., V. Segre, and R. H. Waldman. 1968. Optimal antibiotic therapy in cholera. Bull. WHO. 39:239-245.

53. Pierce, N. F., and A. Mondal. 1974. Clinical features of cholera. In Cholera. D. Barua, and W. Burrows, editors. W. B. Saunders Co. Philadelphia. 209-220.

54. Holmberg, S. D., W. L. Schell, G. R. Fanning, I. K. Wachsmuth, F. W. Hickman-Brenner, P. A. Blake, D. J. Brenner, and J. J. Farmer III. 1986. Aeromonas intestinal infections in the United States. Ann. Intern. Med. 105:683-689.

55. Sears, S. D., K. Richardson, C. Young, C. D. Parker, and M. M. Levine. 1984. Evaluation of the human immune response to outer membrane proteins of Vibrio cholerae. Infect. Immun. 44:439-444.

56. Black, R. E., M. H. Merson, B. Rowe, P. R. Taylor, A. R. M. A. Alim, R. J. Gross, and D. A. Sack. 1981. Enterotoxigenic Escherichia coli diarrhoea: acquired immunity and transmission in an endemic area. Bull. WHO. 59:263-268.

57. Levine, M. M., E. S. Caplan, D. Waterman, R. A. Cash, R. B. Hornick, and M. J. Snyder. 1977. Diarrhea caused by Escherichia coli that produce only heat stable enterotoxin. Infect. Immun. 17:78-82.

58. Kantele, A. M., R. Takanen, and H. Arvilommi. 1988. Immune response to acute diarrhea seen as circulating antibody-secreting cells. J. Infect. Dis. 158:1011-1016.

59. Black, R. E., M. M. Levine, M. L. Clements, C. R. Young, A.-M. Svennerholm, and J. Holmgren. 1987. Protective efficacy in 
humans of killed whole-Vibrio oral cholera vaccine with and without the B subunit of cholera toxin. Infect. Immun. 55:1116-1120.

60. Clemens, J. D., D. A. Sack, J. R. Harris, J. Chakraborty, M. R. Khan, B. F. Stanton, B. A. Kay, M. U. Khan, M. Yunus, W. Atkinson, A.-M. Svennerholm, and J. Holmgren. 1986. Field trial of oral cholera vaccines in Bangladesh. Lancet. 2:124-127.

61. Levine, M. M. 1987. Escherichia coli that cause diarrhea: Enterotoxigenic, enteropathogenic, enteroinvasive, enterohemorrhagic, and enteroadherent. J. Infect. Dis. 166:377-389.

62. Honda, T., K. Kasemsuksakul, T. Oguchi, M. Kohda, and T. Miwatani. 1988. Production and partial characterization of pili on non-O1 Vibrio cholerae. J. Infect. Dis. 157:217-218.

63. Levine, M. M. 1985. Escherichia coli infections. N. Engl. J. Med. 313:445-447.

64. Darfeuille-Michaud, A., C. Forestier, B. Joly, and R. Cluzel. 1986. Identification of a nonfimbrial adhesive factor of an enterotoxigenic Escherichia coli strain. Infect. Immun. 52:468-475.

65. Kaper, J., H. Lockman, R. R. Colwell, and S. W. Joseph. 1979. Ecology, serology, and enterotoxin production of Vibrio cholerae in Chesapeake Bay. Appl. Environ. Microbiol. 37:91-103.

66. Shehabi, A. A., and S. H. Richardson. 1985. Enterotoxigenicity of clinical isolates of non-O1 Vibrio cholerae. Zentralbl. Bakteriol. Mikrobiol. Hyg. Ser. A260:311-318.

67. Takeo, T., N. Tominaga, S. Yoshimura, Y. Shimonishi, S. Hara, T. Inoue, and A. Miyama. 1985. Isolation, primary structure and synthesis of heat-stable enterotoxin produced by Yersinia enterocolitica. Eur. J. Biochem. 152:199-206.

68. Ryder, R. W., I. K. Wachsmuth, A. E. Buxton, D. G. Evans, H. L. DuPont, E. Mason, and F. F. Barrett. 1976. Infantile diarrhea produced by heat-stable enterotoxigenic Escherichia coli. $N$. Engl. J. Med. 295:849-855.

69. Gyles, C. L., J. B. Stevens, and J. A. Craven. 1971. A study of Escherichia coli strains isolated from pigs with gastrointestinal disease. Can. J. Comp. Med. 35:258-266.

70. Falkow, S. 1988. Molecular Koch's postulates applied to microbial pathogenicity. Rev. Infect. Dis. 10:S274-S277.

71. Roberts, N. C., R. J. Siebeling, J. B. Kaper, and H. B. Bradford. 1982. Vibrios in the Louisiana Gulf Coast environment. Microb. Ecol. 8:299-312.

72. Hanchalay, S., J. Seriwatana, P. Echeverria, J. Holmgren, C. Tirapat, S. L. Moseley, and D. N. Taylor. 1985. Non-O1 Vibrio cholerae in Thailand: homology with cloned cholera toxin genes. J. Clin. Microbiol. 21:288-9. 